\title{
Sexual ornaments reveal the strength of melanization immune response and longevity of male paper wasps
}

\author{
André Rodrigues de Souza ${ }^{\mathrm{a}, \mathrm{b}, *}$, Talitta Guimarães Simões ${ }^{\mathrm{b}}$, Markus J. Rantala ${ }^{\mathrm{c}}$, \\ Eduardo Fernando Santos ${ }^{\mathrm{d}}$, José Lino-Netto ${ }^{\mathrm{e}}$, Fábio Santos do Nascimento ${ }^{\mathrm{a}}$ \\ ${ }^{\text {a }}$ Departamento de Biologia, Faculdade de Filosofia Ciências e Letras de Ribeirão Preto, Universidade de São Paulo, São Paulo, Brazil \\ ${ }^{\mathrm{b}}$ Departamento de Entomologia, Universidade Federal de Viçosa, Minas Gerais, Brazil \\ ${ }^{\mathrm{c}}$ Department of Biology and Turku Brain and Mind Centre, University of Turku, Turku, Finland \\ d Departamento de Zoologia e Botânica, Instituto de Biociências, Letras e Ciências Exatas, Universidade Estadual Paulista “Júlio de Mesquita Filho", São José do Rio Preto, \\ Brazil \\ e Departamento de Biologia Geral, Universidade Federal de Viçosa, Minas Gerais, Brazil
}

\section{A R T I C L E I N F O}

\section{Keywords:}

Hymenoptera

Immunity

Sexual selection

Female choice

Ornaments

Sexually selected signals

\begin{abstract}
A B S T R A C T
It has been recently suggested that female mate choice, based on sexually selected ornaments, is an important component of social wasps' reproductive biology. The correlates of male ornaments that could be of a female's interest, however, remain to be investigated. Males of the Neotropical paper wasp Polistes simillimus have sexually dimorphic melanin-based black spots on their faces. In this species, male spots work like sexual ornaments, as it has been experimentally demonstrated that females prefer sexual partners with a higher proportion of black pigment on their faces. We have shown that, under laboratory conditions, male sexual ornamentation positively predicts the strength of the melanization immune response and longevity. Therefore, in $P$. simillimus, melanin-based facial patterns (ornaments) seem to be honest indicators of male quality.
\end{abstract}

\section{Introduction}

Across the animal taxa, expression of the secondary sexual traits of males often provides females with information about the strength of their immune defense (birds: Gonzalez et al., 1999; Saks et al., 2003; Bonato et al., 2009; lizards: Martín et al., 2007; mice: Penn and Potts 1998, 1999; insects and arachnids: reviewed in Lawniczak et al., 2007) and longevity (Birds, fishes, spiders, and insects: reviewed in Jennions et al., 2001). In such cases, the female sexual preference for ornamented males may be adaptive (Andersson, 1994). Specifically, if males with preferred ornaments have a stronger immune defense and/or higher expected longevity (positive associations), then choosy females may potentially avoid copulation with sick males (Hurst et al., 1995; Able, 1996). Additionally, if these fitness-related components are heritable, then females may increase the viability of their offspring (Hamilton and Zuk, 1982; Møller, 1990; Kurtz and Sauer, 1999; Johnsen et al., 2000).

Social insects have become important model organisms for ecological immunology. These insects are particularly vulnerable to pathogens (Schmid-Hempel, 1998; Cavalleri et al., 2013; Kappeler et al., 2015). The spatial proximity and frequent interactions between many closely related individuals, which are typical aspects of eusocial life, are supposed to facilitate the spread of diseases (Schmid-Hempel, 1998; Hughes and Boomsma, 2004; Baer et al., 2005). Not surprisingly, they have evolved in a number of ways to suppress parasites (SchmidHempel, 1998). In addition to behavioral adaptations, physiological adaptations are common, such as, the use of self-produced antimicrobial chemicals from the metapleural glands, feces or venom, as well as vertical (parent to offspring) and horizontal (among individuals from the same generation) transference of immunity (reviewed in Cremer et al., 2007). Social insects are also important model organisms for studying longevity. In most organisms, high reproductive output is associated with reduced longevity, as it results from the energetic costs of reproduction and mating (Williams, 1957; Monroy and Korb, 2016), but social insects seem to have avoided this tradeoff (Rueppell, 2009; Loof, 2011). Indeed, queens among honey bees, leaf-cutting ants, and termites are among the most long-lived insects and these queens also have one of the highest known reproductive rates (Jemielity et al., 2005). Additionally, females of Polistes dominula paper wasps seem to mate mainly with mature experienced males - the males that have defended mating territories for a relatively longer time, suggesting that longevity may be related to male reproductive success in paper wasps ("The marathoner hypothesis", Beani, 1996). To our knowledge, the

\footnotetext{
* Corresponding author at: Departamento de Biologia, Faculdade de Filosofia Ciências e Letras de Ribeirão Preto, Universidade de São Paulo, São Paulo, Brazil.

E-mail address: andrebioufjf@gmail.com (A.R. de Souza).
} 
relationship between male immunology, longevity, and sexual ornamentation has not been investigated in eusocial species so far. Sexual ornamentation in male social insects was first reported more than two decades ago (Stenogastrine wasps: Beani and Turillazzi, 1999), but it was only recently that this topic received considerable attention (Izzo and Tibbetts, 2012; De Souza et al., 2014, 2016; reviewed in Baer 2014, 2015; Beani et al., 2014).

Polistes paper wasps have a "lek-like" mating system, ranging from species where non-aggressive males perform collective patrol (i.e. swarms) in places where sexually receptive females are likely to be found (i.e. different branches in a tree) to species where aggressive males defend the exclusive mating territories that females visit to choose a mate (Beani and Turillazzi, 1988). Common to all those cases, copulations occur mainly out of the nest and females seem to be single mated (Strassmann, 2001; but see Seppä et al., 2011). At least in some species, the female's choice of a sexual partner may depend on male visual ornaments, for example, color spots on male's head (Polistes simillimus, De Souza et al., 2014) and abdomen (P. dominula, Izzo and Tibbetts, 2012). This gives an opportunity to investigate the relationship between ornamentation, male quality, and mate choice.

Males of the Neotropical paper wasps, Polistes simillimus, have a variable proportion of the face black pigmented, presumably melaninbased (Fig. 1). We already know that this sexually dimorphic trait affects male reproductive success, as females prefer sexual partners with a large proportion of black pigment on the face (De Souza et al., 2014). Although ornament manipulation clearly points out that females evaluate male facial black spots (De Souza et al., 2014), we know nothing about the potential information that females obtain from male signals. In this study, we ask whether male ornamentation conveys information about its ability to exhibit a melanization immune response. This occurs when a foreign object that is too large to be phagocytized penetrates the insect body. The cellular and humoral process lead to the aggregation of hemocytes around the object as well as deposition of melanin, often resulting in a dark capsule around it (Salt, 1970). This process of melanotic encapsulation is a way by which arthropods neutralize, particularly endoparasitoid wasps and flies (Salt, 1970; Kraaijeveld et al., 2001a,b), and also virus-infected cells (Washburn et al., 1996). The easiest and probably the most informative way to assess the strength of immune defense in insects is to insert a nylon monofilament implant into the body cavity, to measure the melanization score of the implant. It has been shown that the ability to better melanize a nylon monofilament is strongly related to a lower likelihood of being successfully parasitized (Doums and Schmid-Hempel, 2000) as well as a higher ability to encapsulate a real pathogen (Paskewitz and Riehle, 1994; Gorman et al., 1996; Rantala and Roff, 2007), real parasitoid (Smilanich et al., 2009), or real parasite (Nagel et al., 2011). Also, we ask whether male ornamentation conveys information about its expected longevity. At least in social insects, living longer is associated with higher reproductive output (Rueppell, 2009; Loof, 2011), so that longevity could also be considered as an indicator of male quality. If male ornamentation advertises its quality to females, we predict a positive association between the proportion of the black pigmentation on the face and the melanization score of the nylon implant and/or longevity.

\section{Material and methods}

\subsection{Study organism, study place, male collection, and maintenance}

New colonies of $P$. simillimus are started by one or a few inseminated females (Prezoto, 2001). In Brazil, most of the new colonies are founded during the hot/humid season, from August to December, although it is possible for these wasps to start colonies during any period of the year (Prezoto, 2001). During the colony cycle, wasps produce many generations of workers followed by the reproductives (males and future foundresses), so that around February and April, which is the end of the hot/humid period, giant colonies, with around 1000-4000 nest cells, and hundreds of adults (including reproductive forms) and immature individuals are observed (Gobbi et al., 1993). Reproductive wasps leave the colony to copulate (the mating places are not known), but even as males assume a solitary life out of the nest, reproductive females aggregate over the old natal nest or around its surroundings till the next founding season (Prezoto, 2001). These aggregations, comprised of 78-500 females, are observed during the cold/dry period, between March and July (Prezoto, 2001). As soon as the next warm/humid period approaches, females leave the aggregates to start new colonies (Gobbi et al., 1993).

On 25 April 2015 and on 20 April 2016, male-producing nests of $P$. simillimus (a total of 180 males from 11 nests) were collected in Viçosa, Minas Gerais state, Southeast of Brazil $\left(20^{\circ} 48^{\prime} \mathrm{S}\right.$, $42^{\circ} 51^{\prime} \mathrm{W}$, elevation $800 \mathrm{~m}$ ). In the laboratory, the nests (without adult wasps) were individually kept in plastic containers of $5 \mathrm{~L}$. Subsequently, we inspected the nests daily to check for the presence of adult wasps. Newly emerged males were individualized in plastic containers of $0.5 \mathrm{~L}$ and provided with water and food (sucrose solution 50\%). Males collected in 2015 (87 from three nests) were submitted to an immunological assay after $24 \mathrm{~h}$ of emergence. Males collected in 2016 (93 from eight nests) were kept in plastic containers to verify their longevity (the containers were checked daily). The laboratory conditions during the assays were around $28^{\circ} \mathrm{C}, 70 \%$ relative humidity, and a light cycle of $12 \mathrm{~h}$ light (12 h dark).

\subsection{Immunological assay}

To begin with, we anesthetized the males by putting them in a freezer for two minutes. Subsequently, to elicit a melanization response, we inserted a piece of a nylon filament $(2 \mathrm{~mm}$ length and $0.2 \mathrm{~mm} \emptyset$ ) in the ventral intersegmental membrane, between each male's third and fourth abdominal sternite (Doums and Schmid-Hempel, 2000). We put the males back into their individual plastic containers for $24 \mathrm{~h}$. Following that, we dissected the nylon filament out and mounted it on a microscope slide. All the materials used during this procedure were previously sterilized with ethanol.

\subsection{Measuring the melanization score of the nylon filament}

We quantified the darkness of each filament (Doums and SchmidHempel, 2000) - the darker the filament the higher the melanization score. Thus, we estimated how dark each filament was by using standard digital photography, a quantitative and objective way to measure color variation (Stevens et al., 2007). Thus, we examined one side of

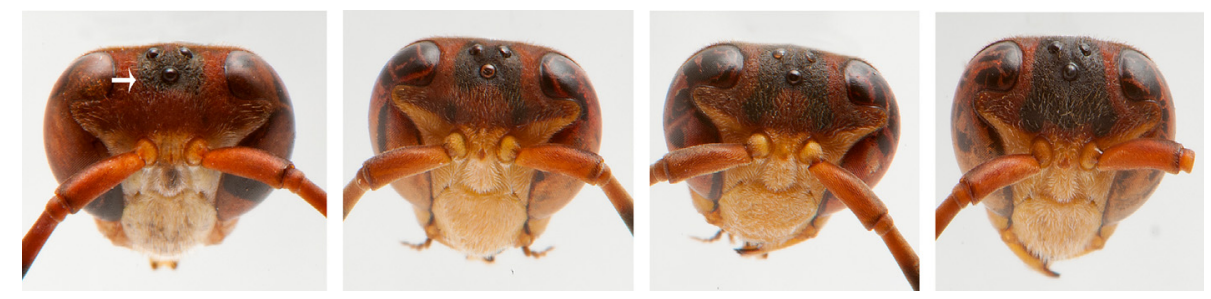

Fig. 1. Portraits of $P$. simillimus male faces showing variation in the black pigmentation (arrow). From the left to the right, there is an increase in the proportion of vertex black pigmented (sexual ornamentation). 
Table 1

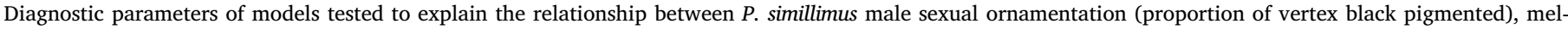

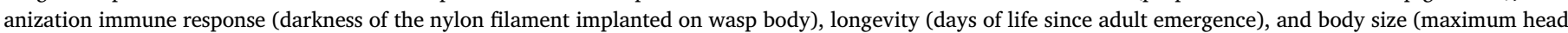

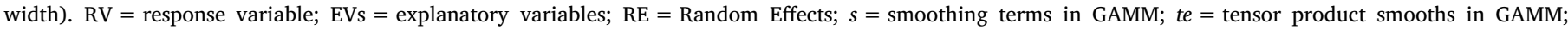
$t i=$ tensor product interaction in GAMM. Asterisks indicate the best fit models.

\begin{tabular}{|c|c|c|c|c|c|}
\hline $\mathrm{RV} \sim \mathrm{EVs}$ & Adj. $\mathrm{R}^{2}$ & Estimate & $\mathrm{P}$ & $\begin{array}{l}\text { RE } \\
\text { Intercept } \\
\text { (Residual) }\end{array}$ & AIC \\
\hline $\begin{array}{l}\text { ornamentation }=\text { melanization immune response }+ \text { body } \\
\text { size }+ \text { melanization immune response, body size }\end{array}$ & 0.076 & $\begin{array}{l}\text { Intercept: } 0.358 \\
\text { s(melanization immune } \\
\text { response): } 1.000 \\
\text { te(body size): } 1.000 \\
\text { ti(melanization immune } \\
\text { response, body size): } 1.000\end{array}$ & $\begin{array}{l}\text { Intercept: }<0.001 \\
\text { s(melanization immune response): } \\
0.011 \\
\text { te(body size): } 0.094 \\
\text { ti(melanization immune response, } \\
\text { body size): } 0.634\end{array}$ & $\begin{array}{l}9.4 \times 10-3 \\
(0.087)\end{array}$ & -128.597 \\
\hline ornamentation $=$ melanization immune response + body size & 0.077 & $\begin{array}{l}\text { Intercept: } 0.360 \\
\text { s(melanization immune } \\
\text { response): } 1.000 \\
\text { te(body size): } 1.000\end{array}$ & $\begin{array}{l}\text { Intercept: }<0.001 \\
\text { s(melanization immune response): } \\
0.014 \\
\text { te(body size): } 0.113\end{array}$ & $\begin{array}{l}7.9 \times 10-5 \\
(0.088)\end{array}$ & -134.294 \\
\hline *ornamentation $=$ melanization immune response & 0.057 & $\begin{array}{l}\text { Intercept: } 0.360 \\
\mathrm{~s} \text { (melanization immune } \\
\text { response): } 1.000\end{array}$ & $\begin{array}{l}\text { Intercept: }<0.001 \\
\text { s(melanization immune response): } \\
0.021\end{array}$ & $\begin{array}{l}5.2 \times 10-3 \\
(0.089)\end{array}$ & -135.734 \\
\hline ornamentation = te(body size) & 0.010 & $\begin{array}{l}\text { Intercept: } 0.361 \\
\text { te(body size): } 1.000\end{array}$ & $\begin{array}{l}\text { Intercept: }<0.001 \\
\text { te(body size): } 0.188\end{array}$ & $\begin{array}{l}9.5 \times 10-7 \\
(0.091)\end{array}$ & -132.169 \\
\hline *ornamentation $=$ longevity + body size + longevity, body size & 0.171 & $\begin{array}{l}\text { Intercept: } 0.263 \\
\text { s(longevity): } 1.000 \\
\text { te(body size): } 1.000 \\
\text { ti(longevity, body size): } \\
2.251\end{array}$ & $\begin{array}{l}\text { Intercept: }<0.001 \\
\text { s(longevity): }<0.001 \\
\text { te(body size): }<0.001 \\
\text { ti(longevity, body size): } 0.015\end{array}$ & $\begin{array}{l}4.4 \times 10-2 \\
(0.071)\end{array}$ & -193.598 \\
\hline ornamentation $=$ longevity + body size & 0.085 & $\begin{array}{l}\text { Intercept: } 0.256 \\
\text { s(longevity): } 1.000 \\
\text { te(body size): } 1.000\end{array}$ & $\begin{array}{l}\text { Intercept: }<0.001 \\
\text { s(longevity): }<0.001 \\
\text { te(body size) }:<0.001\end{array}$ & $\begin{array}{l}5.1 \times 10-2 \\
(0.075)\end{array}$ & -192.451 \\
\hline ornamentation $=$ longevity & 0.106 & $\begin{array}{l}\text { Intercept: } 0.269 \\
\text { s(longevity): } 1.000\end{array}$ & $\begin{array}{l}\text { Intercept: }<0.001 \\
\text { s(longevity): } 0.001\end{array}$ & $\begin{array}{l}4.8 \times 10-2 \\
(0.083)\end{array}$ & -177.838 \\
\hline ornamentation $=$ body size & -0.012 & $\begin{array}{l}\text { Intercept: } 0.257 \\
\text { te(body size): } 1.000\end{array}$ & $\begin{array}{l}\text { Intercept: }<0.001 \\
\text { te(body size): }<0.001\end{array}$ & $\begin{array}{l}5.5 \times 10-2 \\
(0.080)\end{array}$ & -182.738 \\
\hline longevity $=$ body size & -0.024 & $\begin{array}{l}\text { Intercept: } 3.667 \\
\text { s(body size): } 8.466\end{array}$ & $\begin{array}{l}\text { Intercept: }<0.001 \\
\text { s(body size) }:<0.001\end{array}$ & $0.363(1.000)$ & - \\
\hline melanization immune response $=$ body size & 0.001 & $\begin{array}{l}\text { Intercept: } 5.077 \\
\text { s(body size): } 2.683\end{array}$ & $\begin{array}{l}\text { Intercept: }<0.001 \\
\text { s(body size): } 0.056\end{array}$ & $0.048(1.000)$ & - \\
\hline
\end{tabular}

each filament, by taking a single 8-bit RAW digital picture with a Panasonic Cybershot camera connected to a stereomicroscope with a constant light source and a constant white background. The white balance was calibrated with a Kodak $18 \%$ gray card. We used the Adobe Photoshop Light room software (version 4.1) to convert the pictures to JPEG. The JPEG pictures were transferred to the Image $J$ application (available online at http://rsbweb.nih.gov/ij/), to estimate the relative melanization score, defined as the mean relative darkness of each filament, which ranged between 0 (totally white) and 255 (totally black). Of note, not all males were included in the analysis, as some of them died before the end of the immunological test $(\mathrm{N}=10)$ or groomed the filament out $(\mathrm{N}=2)$. As a result, 75 out of 87 males were included in the analysis. Additionally, the melanization score was measured by a researcher who only had access to the pictures of the nylon filaments, while male sexual ornamentation was measured by another researcher, who only had access to the pictures of male faces (described below). These researchers were not involved in the immunological assay. This procedure avoided researcher bias.

\subsection{Measuring male ornaments}

After the immunological assay or after male death, we froze the wasps to measure the ornaments. The black pigmentation on the male face is concentrated in the upper portion of the head, around the ocelli, an area known as the vertex (Fig. 1). By using the same equipment for image acquisition and the analysis described above, we took a picture of each male's head to calculate the proportion of black pigmentation in this region, excluding the area of the ocelli and antennal sockets (for additional details, see De Souza et al., 2014). The proportion of the vertex black pigmented seems to be the active visual component that females look for during their mate choice (De Souza et al., 2014). We also measured the maximum head width of each male, which is a good correlate of male body size (Eickwort, 1969).

\subsection{Statistical analysis}

To examine how male ornamentation is associated with immunocompetence, we ran General Additive Mixed Models (GAMM), which was preferred, because it allows the inclusion of non-linear relationships, non-parametric approaches, and interaction, between covariates. In these models, the proportion of the vertex black pigmented was entered as the dependent variable, while the melanization score of the nylon filament and male head width (a proxy for male body size) were entered as covariates. We used these variables (as well as their interactions) to fit simple and multiple models. We also used the GAMM to examine how male ornamentation is associated with longevity. Thus, the proportion of vertex black pigmented was entered as the dependent variable, while longevity (quantified as days since adult emergence) and male head width were entered as covariates. Again, we used these variables (as well as their interactions) to fit simple and multiple models. Finally, we modeled longevity (dependent variable) with body size (covariate), also using GAMM. The nest origin was used as a random factor in all models. The best-fitted model was selected based on the Akaike information criterion (AIC). Before fitting all models, the Grubb́s test was applied to detect the presence of outliers, which were excluded from the dataset. All statistical analyses were performed with the program $R$ version 3.2.2 (R Development Core Team 2015), using functions of the package $m g c v$ version 1.8-8. The level of significance was set at $5 \%$. The raw data table used for statistical analysis is available as a supplementary electronic material (S1). 


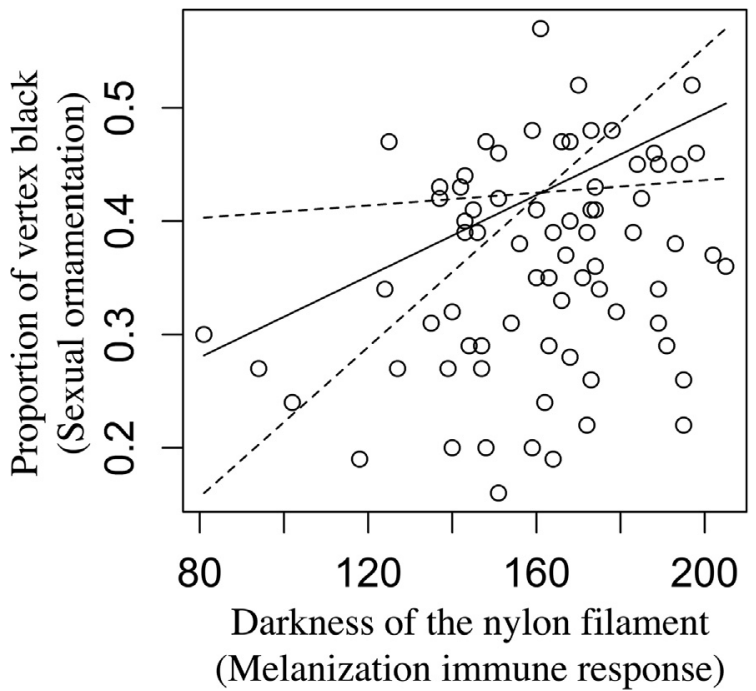

Fig. 2. Relationship between the proportion of vertex black pigmented (sexual ornamentation) and the darkness of the nylon filament (melanization immune response) in males of $P$. simillimus. Each circle represents a male. Solid line represents the smoothing fitted model, while dotted lines indicate the $95 \%$ confidence band. Males with a higher proportion of vertex black pigmented also exhibit a higher melanization score.

\section{Results}

\subsection{Variability in male ornamentation, melanization immune response, longevity, and body size}

The proportion of the vertex black pigmented ranged from $7 \%$ to $57 \%$, thus resulting in different male facial patterns (Fig. 1). Similarly, the melanization score of the nylon filament ranged between 81 and 205 arbitrary units. Male longevity was variable, ranging between 1 and 123 days. Finally, the male body size, inferred from the maximum head width, ranged from 2.9 to $3.55 \mathrm{~mm}$.

\subsection{Male ornamentation is associated with melanization immune response}

In the best fitted model, the proportion of face black pigmented was positively associated with the melanization score of the nylon filament (Table 1). This shows that males with relatively bigger black spots on the face had a higher melanization score (Fig. 2).

\subsection{Male ornamentation is positively associated with longevity and negatively associated with body size}

In the best fitted model, the proportion of face black pigmented was associated with longevity, body size, and their interaction (Table 1). Thus, overall, males with relatively bigger black spots on the face lived longer and they had smaller bodies (Fig. 3). Males with large body size, despite overall less ornamented, could still live longer, if they had relatively more ornamentation (Fig. 3). Male longevity was not related to the body size (Table 1).

\section{Discussion}

The high variability in the strength of melanization immune response and longevity reported here for $P$. simillimus suggests that males are not equally fit. Thus, from the female's perspective, some sexual partners are likely to be fitter than others. More importantly, these differences seem to be revealed by the male facial pattern (sexual ornamentation), providing a basis for the female's choice of potential sexual partners.

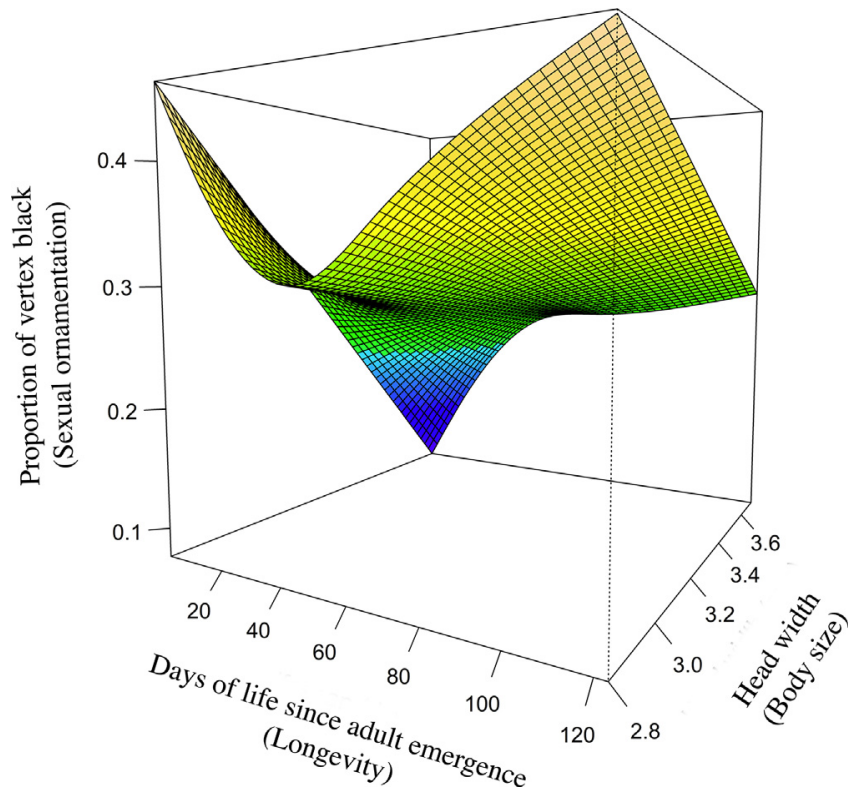

Fig. 3. Relationship between the proportion of vertex black pigmented (sexual ornamentation), days of life since adult emergence (longevity), and the head width (body size) in males of $P$. simillimus.

In $P$. simillimus, females prefer more ornamented males, that is, the individuals with a larger proportion of vertex black pigmented (De Souza et al., 2014). We found this trait to be positively related to the male melanization immune response. As a result, by choosing males based on these sexually selected visual signals, females are more likely to assure high-quality and potentially, better disease-resistant sexual partners. When sexual ornamentation reveals the male's ability to cope with pathogens, the choosy females may benefit from heritable parasite resistance in the brood. According to the parasite-mediated sexual selection hypothesis, this benefit is supposed to drive the evolution of female mate choice for ornamented males, especially under significant prevalence of parasites at the population level (Hamilton and Zuk, 1982). Both temperate and Neotropical Polistes paper wasps are common hosts of strepsipteran abdominal endoparasites (Beani, 2006; Kudô et al., 2014), although, to date, we do not have a formal sense of its prevalence in our studied population (as well as the prevalence of other organisms that could be neutralized by melanization). Additionally, no parasitism or outward sign of disease was found in any wasp included in this study, as well as in a previous study with the same population (De Souza et al., 2014). Therefore, more focused research is necessary before drawing conclusive statements about whether parasite-mediated sexual selection plays a role in the evolution of female mate choice in $P$. simillimus.

The positive relationship between the proportion of vertex black pigmented and male ability to melanize a nylon filament reported here can occur when the "size" of a sexual trait and the immune function are both condition-dependent (Van Noordwijk and de Jong, 1986; Møller and Saino, 1994; Møller et al., 1999). There is evidence that in insects, both melanin-based sexual ornaments and melanin-based immunity may be condition-dependent (Siva-Jothy and Thompson, 2002; Cotton et al., 2004; Schmid-Hempel, 2005; Izzo and Tibbetts, 2015; Støehr, 2006). In this sense, males in a poor condition would have both smaller sexual traits and immune functions than do males in a good condition. A mechanistic link between black spots on a male's face and melanization score could arise if the same pigment, the melanin, is used in both male ornaments and immune defense, as it seems to be the case in calopterygidae damsel flies (Rantala et al., 2000; Siva-Jothy, 2000). Moreover, male ornaments and immune defense may compete for tyrosin (a precursor of melanin, Støehr, 2006), which is specially limited 
in a species with an insect-based diet, such as wasps. These explanations agree with the immunocompetence handicap hypothesis, which posits that elaborate sexual ornaments impose immunological costs (Wedekind and Folstad, 1994). This provides a likely mechanical explanation for the honesty of male $P$. simillimus visual signals. In support, black pigmentation is not spread over the male body, as it would be expected for a less costly pigmentation. Instead, black pigmentation is restricted to the male vertex.

Of note, when plotting the melanization immune response against sexual ornamentation (Fig. 2), it is clear that most individuals fall into the bottom-right of the graph. This kind of distribution suggests that (i) having a strong immune response might be more important than having better ornamentation or (ii) that the immune systems of many individuals have been activated at an immature stage, hence they have invested more in the immune system than in ornamentation.

Male ornamentation is not only associated with immune response, it also predicts male longevity. This association, also found in many other animals (meta-analysis by Jennions et al., 2001), further suggests that males with relatively bigger black spots on the face are high-quality sexual partners. In most social insects, the majority of sexual offsprings can only be reared after the production of many sterile workers, which might take many months (Hölldobler and Wilson, 1990). Thus, reproduction in social insects takes a relatively long time. As a result, higher longevity would potentially increase the probability that a queen will live long enough to produce males and gynes. If social insect longevity has a genetic basis (e.g., honey bees: Rinderer et al., 1983), then female choice for ornamented males may result in the production of longer-lived female offsprings, as daughters inherit the entire male genome.

The more ornamented males of $P$. simillimus tend to have small bodies (De Souza et al., 2014, this study). In other wasps, male body size is often related to its quality. For example, during the breeding season, males of $P$. dominula compete aggressively for small territories in the leks, as those are the place where females visit to mate - larger males are more likely to have a territory (Beani and Turillazzi, 1988). In $P$. simillimus, however, male body size does not predict male-male dominance or female mate choice, when wasps interact in a small arena under laboratory conditions (De Souza et al., 2014). In the future, field observation of the $P$. simillimus mating system, which is currently missing, will be essential, to understand the importance of this trade-off between sexual advertisement and body size.

In conclusion, males of the $P$. simillimus paper wasps present striking inter-individual differences in fitness-related components, such as the strength of the immune response towards a nylon filament and longevity (physiological life span) under laboratory conditions. Sexual ornamentation (facial pattern) seems to honestly reveal these traits. Therefore, by preferring more ornamented males (De Souza et al., 2014), P. simillimus females are more likely to pick a high-quality sexual partner.

\section{Funding}

This work was supported by Fundação de Amparo à Pesquisa do Estado de São Paulo (FAPESP) [under the grant 2015/05302-0 to A R de Souza and 2015/25301-9 to F S Nascimento.

\section{Appendix A. Supplementary data}

Supplementary data associated with this article can be found, in the online version, at https://doi.org/10.1016/j.jinsphys.2018.06.002.

\section{References}

Able, D., 1996. The contagion indicator hypothesis for parasite-mediator sexual selection. Proc. Natl. Acad. Sci. U.S.A. 93, 2229-2233.

Andersson, M., 1994. Sexual Selection. Princeton University Press, Princeton.
Baer, B., 2014. Sexual selection in social insects. In: Shuker, D.M., Simmons, L.W. (Eds.), The Evolution of Insect Mating Systems. Oxford University Press, Oxford, pp. 261-274.

Baer, B., 2015. Female choice in social insects. In: Peretti, A.V., Aisenberg, A. (Eds.), Cryptic Female Choice in Arthropods. Springer International Publishing, Switzerland, pp. 461-477.

Baer, B., Krug, A., Boomsma, J.J., Hughes, W.H.O., 2005. Examination of the immune responses of males and workers of the leaf-cutting ant Acromyrmex echinatior and the effect of infection. Insect Soc. 52, 298-303.

Beani, L., 1996. Lek-like courtship in paper-wasps: 'a prolonged, delicate, and troublesome affair'. In: West-Eberhard, M.J. (Ed.), Natural History and Evolution of Paperwasps (Turillazzi S. Oxford University Press, Oxford, England, UK, pp. 113-125.

Beani, L., 2006. Crazy wasps: when a parasite manipulates Polistes phenotype. Ann. Zool. Fenn. 43, 564-574.

Beani, L., Dessì-Fulgheri, F., Cappa, F., Toth, A., 2014. The trap of sex in social insects: from the female to the male perspective. Neurosci. Biobehav. Rev. 46, 519-533.

Beani, L., Turillazzi, S., 1988. Alternative mating tactics in males of Polistes dominulus (Hymenoptera: Vespidae). Behav. Ecol. Sociobiol. 22, 257-264.

Beani, L., Turillazzi, S., 1999. Stripes display in hover-wasps (Vespidae: Stenogastrinae): a socially costly status badge. Anim. Behav. 57, 1233-1239.

Bonato, M., Evans, M.R., Hasselquist, D., Cherry, M.I., 2009. Male coloration reveals different components of immunocompetence in ostriches Struthio camelus. Anim Behav. 77, 1033-1039.

Cavalleri, A., De Souza, A.R., Prezoto, F., Mound, L.A., 2013. Egg predation within the nests of social wasps: a new genus and species of Phlaeothripidae, and evolutionary consequences of Thysanoptera invasive behaviour. Biol. J. Linn. Soc. 109, 332-341.

Cotton, S., Fowler, K., Pomiankowski, A., 2004. Do sexual ornaments demonstrate heightened condition-dependent expression as predicted by the handicap hypothesis? Proc. R. Soc. Lond. B 271, 771-783.

Cremer, S., Armitage, S.A., Schmid-Hempel, P., 2007. Social immunity. Curr. Biol. 17 (16), R693-R702.

De Souza, A.R., Júnior, C.A.M., Nascimento, F.S., Lino-Neto, J., 2014. Sexy faces in a male paper wasp. PLoS One, e98172.

De Souza, A.R., Lino-Neto, J., Tibbetts, E.A., Turillazzi, S., Beani, L., 2016. The leks of Polistes dominula paper wasps: tiny abdominal spots play a critical role in male attacks toward potential rivals. Ethol. Ecol. Evol. 29, 410-419.

Doums, C., Schmid-Hempel, P., 2000. Immunocompetence in workers of a social insect, Bombus terrestris L., in relation to foraging activity and parasitic infection. Can. J. Zool. 78, 1060-1066.

Eickwort, K., 1969. Separation of the caste of Polistes exclamans and notes on its biology (Hymenoptera: Vespidae). Insect Soc. 16, 67-72.

Gobbi, N., Fowler, H.G., Chaud-Netto, J., Nazareth, S.L., 1993. Comparative colony productivity of Polistes simillimus and Polistes versicolor (Hymenoptera:Vespidae) and the evolution of paragyny in the Polistinae. Zool. Jb Physiol. 97, 239-243.

Gonzalez, G., Sorci, G., Møller, A.P., Ninni, P., Haussy, C., De Lope, F., 1999. Immunocompetence and condition-dependent sexual advertisement in male house sparrows (Passer domesticus). J. Anim. Ecol. 68, 1225-1234.

Gorman, M.J., Cornel, A.J., Collins, F.H., Paskewitz, S.M., 1996. A shared genetic mechanism for melanotic encapsulation of CM-sephadex beads and a malaria parasite, Plasmodium cynomolgi B, in the Mosquito Anopheles gambiae. Exp. Parasitol. 84, 380-386.

Hamilton, W., Zuk, M., 1982. Heritable true fitness and bright birds a role for parasites? Science 218, 384-387.

Hölldobler, B., Wilson, E.O., 1990. The Ants. Harvard University Press, Harvard.

Hughes, W.O., Boomsma, J.J., 2004. Genetic diversity and disease resistance in leafcutting ant societies. Evolution 58, 1251-1260.

Hurst, G.D., Sharpe, R.G., Broomfield, A.H., Walker, L.E., Majerus, T.M., Zakharov, I.A. Majerus, M.E., 1995. Sexually transmitted disease in a promiscuous insect Adalia bipunctata. Ecol. Entomol. 20, 230-236.

Izzo, A.S., Tibbetts, E.A., 2012. Spotting the top male: sexually selected signals in male Polistes dominulus wasps. Anim. Behav. 83, 839-845.

Izzo, A., Tibbetts, E.A., 2015. Heightened condition-dependence of a sexually selected signal in male Polistes dominulus paper wasps. Ethology 121, 586-592.

Jemielity, S., Chapuisat, M., Parker, J.D., Keller, L., 2005. Long live the queen: studying aging in social insects. Age 27, 241-248.

Jennions, M.D.A., Møller, P., Petrie, M., 2001. Sexually selected traits and adult survival: a meta-analysis. Q. Rev. Biol. 76, 3-36.

Johnsen, A., Andersen, V., Sunding, C., Lifjeld, J.T., 2000. Female bluethroats enhance offspring immunocompetence through extra-pair copulations. Nature 406, 296-299.

Kappeler, P.M., Cremer, S., Nunn, C.L., 2015. Sociality and health: impacts of sociality on disease susceptibility and transmission in animal and human societies. Phil. Trans. R. Soc. B 370, 20140116

Kraaijeveld, A.R., Limentani, E.C., Godfray, H.C.J., 2001b. Basis of the trade-off between parasitoid resistance and larval competi- tive ability in Drosophila melanogaster. Proc. R. Soc. Lond. B 268, 259-261.

Kraaijeveld, A.R., Hutcheson, K.A., Limentani, E.C., Godfray, H.C.J., 2001a. Costs of counterdefenses to host resistance in a parasitoid of Drosophila. Evolution 55, 1815-1821.

Kudô, K., Komatsu, K., Mateus, S., Zucchi, R., Nascimento, F.S., 2014. Presence of Strepsiptera parasites in the independent-founding wasp, Polistes satan. Sociobiology 61, 237-238.

Kurtz, J., Sauer, K.P., 1999. The immunocompetence handicap hypothesis: testing the genetic predictions. Proc. R. Soc. Lond. B 266, 2515-2522.

Lawniczak, M.K., Barnes, A.I., Linklater, J.R., Boone, J.M., Wigby, S., Chapman, T., 2007. Mating and immunity in invertebrates. Trends Ecol. Evol. 22, 48-55.

Loof, A.D., 2011. Longevity and aging in insects: is reproduction costly; cheap; beneficial 
or irrelevant? A critical evaluation of the 'trade-off' concept. J. Insect Physiol. 57, $1-11$.

Martín, J., Civantos, E., Amo, L., López, P., 2007. Chemical ornaments of male lizards Psammodromus algirus may reveal their parasite load and health state to females. Behav. Ecol. Sociobiol. 62, 173-179.

Møller, A.P., 1990. Effects of a haematophagous mite on the barn swallow (Hirundo rustica): a test of the Hamilton and Zuk hypothesis. Evolution 44, 771-784.

Møller, A.P., Christe, P., Lux, E., 1999. Parasitism, host immune function, and sexual selection. Q. Rev. Biol. 74, 3-20.

Møller, A.P., Saino, N., 1994. Parasites, immunology of hosts, and host sexual selection. J. Parasitol. 80, 850-858.

Monroy, K.J., Korb, J., 2016. Ageing and the reversal of the fecundity/longevity trade-off in social insects. Curr. Opin. Insect Sci. 16, 7-10.

Nagel, L., Mlynarek, J.J., Forbes, M.R., 2011. Immune response to nylon filaments in two damselfly species that differ in their resistance to ectoparasitic mites. Ecol. Entomol. 36, 736-743.

Paskewitz, S., Riehle, M.A., 1994. Response of Plasmodium refractory and susceptible strains of Anopheles gambiae to inoculated Sephadex beads. Dev. Comp. Immunol. 18, 369-375.

Penn, D., Potts, W., 1998. How do major histocompatibility complex genes influence odor and mating preferences. Adv. Immunol. 69, 411-436.

Penn, D.J., Potts, W.K., 1999. The evolution of mating preferences and major histocompatibility complex genes. Am. Nat. 153, 145-164.

Prezoto F., 2001. Estudos biológicos e etológicos de Polistes (Aphanilopterus) simillimus Zikán, 1951. PhD Thesis. Universidade Estadual Paulista Julio de Mesquita Filho, Brazil.

Rantala, M.J., Koskimäki, J., Suhonen, J., Taskinen, J., Tynkkynen, K., 2000. Immunocompetence, developmental stability and wing spot size in Calopteryx splendens. Proc. R. Soc. Lond. B 267, 2453-2457.

Rantala, M.J., Roff, D.A., 2007. Inbreeding and extreme outbreeding cause sex differences in immune defence and life history traits in Epirrita autumnata. Heredity 98, 329-336.

Rinderer, T.E., Collins, A.M., Brown, M.A., 1983. Heritabilities and correlations of the honey bee: response to Nosema apis, longevity, and alarm response to isopentyl acetate. Apidologie 14, 79-85.
Rueppell, O., 2009. Aging of social insects. In: Gadau, J., Fewell, J. (Eds.), Organization of Insect Societies: From Genome to Sociocomplexity. Harvard University Press, Harvard, pp. 51-73.

Saks, L., Ots, I., Hõrak, P., 2003. Carotenoid-based plumage coloration of male greenfinches reflects health and immunocompetence. Oecologia 134, 301-307.

Salt, G.W., 1970. The cellular Defense Reactions of Insects. Cambridge University Press, Cambridge.

Schmid-Hempel, P., 1998. Parasites in Social Insects. Princeton University Press, Princeton.

Schmid-Hempel, P., 2005. Evolutionary ecology of insect immune defenses. Ann. Rev. Entomol. 50, 529-551.

Seppä, P., Fogelqvist, J., Gyllenstrand, N., Lorenzi, M.C., 2011. Colony kin structure and breeding patterns in the social wasp Polistes biglumis. Insect Soc. 58, 345-355.

Siva-Jothy, M.T., 2000. A mechanistic link between parasite resistance and expression of a sexually selected trait in a damselfly. Proc. R. Soc. Lond. B 267, 2523-2527.

Siva-Jothy, M.T., Thompson, J.J., 2002. Short-term nutrient deprivation affects immune function. Physiol. Entomol. 27, 206-212.

Smilanich, A.M., Dyer, L.A., Gentry, G.L., 2009. The insect immune response and other putative defences as effective predictors of parasitism. Ecology 90, 1434-1440.

Stevens, M., Párraga, C.A., Cuthill, I.C., Partridge, J.C., Troscianko, T.S., 2007. Using digital photography to study animal coloration. Biol. J. Linn. Soc. 90, 211-237.

Støehr, A.M., 2006. Costly melanin ornaments: the importance of taxon? Funct. Ecol. 20, 276-281.

Strassmann, J., 2001. The rarity of multiple mating by females in the social Hymenoptera Insect Soc. 48, 1-13.

Van Noordwijk, A.J., de Jong, G., 1986. Acquisition and allocation of resources: their influence on variation in life history tactics. Am. Nat. 128, 137-142.

Washburn, J.O., Kirkpatrick, B.A., Volkman, L.E., 1996. Insect protection against viruses. Nature 383, 767.

Wedekind, C., Folstad, L., 1994. Adaptive or nonadaptive immunosuppression by sex hormones? Am. Nat. 143, 936-938.

Williams, G.C., 1957. Pleiotropy, natural selection, and the evolution of senescence. Evolution 11, 398-411. 